\title{
Um Estudo da Comodidade Como Característica do Produto ou Serviço Capaz de Influenciar a Decisão do Consumidor
}

\author{
Cida Sanches, Hélio Gonçalves de Souza e Marisa Regina Paixão \\ Recebido em: 26/06/2013. Aprovado em: 29/08/2013. Disponibilizado em: 20/12/2013
}

\section{Resumo}

O objetivo da pesquisa é investigar se a comodidade percebida pelo consumidor em relação a um produto ou serviço é uma característica do produto ou serviço que os clientes reconhecem como um diferenciador positivo em relação a outras empresas e, por isso, são atraídos para comprar da empresa. A pesquisa é uma survey com n=214 e fez uso de questionário tipo Likert, especialmente construído e validado. Pode-se afirmar que os respondentes tendem a ser concordantes em pagar o custo da comodidade, o que é mais um ponto a favor de 'comodidade' ser reconhecida como campo da competição.

Palavras-chave: Comodidade, consumo, diferenciador, competição empresarial

\begin{abstract}
The objective of the research is to investigate whether perceived by the consumer regarding a product or service amenity is a feature of the product or service that customers recognize as a positive differentiator over other companies and therefore are attracted to buy the company. The survey is a survey of $n=214$ and made use of Likert questionnaire, specially constructed and validated. It can be stated that respondents tend to be consistent in paying the cost of convenience, which is another point in favor of 'comfort' to be recognized as the field of competition.
\end{abstract}

Keywords: Comfort, consumption, differentiating, business competition 


\section{Introdução}

O objetivo deste trabalho é conceituar comodidade no campo de pesquisa de marketing e avaliar seu potencial como vantagem competitiva para a conquista do cliente. Trata-se de um estudo empírico que explora os determinantes individuais do comportamento do consumidor, especialmente a motivação e o processo de decisão de compra.

Não se discute aqui se a comodidade tem reflexos na confiança, no comprometimento, na voz ativa ou satisfação do consumidor, mas sim se determinadas características de comodidade do produto ou serviço podem atrair clientes e, desta forma, se configuram como vantagem competitiva.

$\mathrm{Na}$ pesquisa in loco os autores observaram as discussões entre os clientes de um pet shop na qual diziam que na hora de decidir pela compra do serviço de banho do cachorro, levavam em conta, se o prestador de serviço pegava e entregava o cão, em função da comodidade, pois utilizava o tempo que seria gasto no transporte para outras atividades mais importantes. A parte contrária afirmava que preferia levar pessoalmente o seu pequeno cão ao pet shop para a tosa, ficar por lá acompanhando o serviço de perto, garantindo que a comodidade pra ela estava representada pela satisfação de poder supervisionar e acompanhar o seu adorável cachorro.

Essa discussão provocou a reflexão de que em ambos os casos os serviços não se diferenciavam pela qualidade intrínseca, mas por características que podem ser consideradas acessórias. Para uma das partes a preferência era dada em função da comodidade que poderia ser obtida na aquisição do serviço. Essencialmente, se busca aqui resposta para a seguinte questão: a comodidade percebida pelo consumidor em relação a um produto ou serviço pode representar vantagem competitiva?

É conveniente aqui conceituar o que é vantagem competitiva. Para Zaccarelli (1996, p.67) a "vantagem competitiva é qualquer característica do produto ou serviço da empresa que os clientes reconhecem como um diferenciador positivo em relação a outras empresas e, por isso, são atraídos para comprar da empresa". A palavra qualquer, diz Zaccarelli (1996), pretende salientar que não é indispensável que a característica, que é a vantagem competitiva, dê um acréscimo de valor para o cliente: "O acréscimo de valor é sempre desejável, porém não é obrigatório; a condição de reconhecimento pelos clientes exclui da estratégia aspectos considerados usualmente como da máxima importância". Notar que os clientes precisam reconhecer a vantagem competitiva e precisam ser atraídos para comprar da empresa.

O problema da pesquisa, desta forma, pode ser assim definido: a comodidade percebida pelo consumidor em relação a um produto ou serviço é uma característica do produto ou serviço que os clientes reconhecem como um diferenciador positivo em relação a outras empresas e, por isso, são atraídos para comprar da empresa?

O problema se insere na esfera da competitividade que faz com que cresça o número de produtos oferecidos para um consumidor, cada vez mais exigente e exclusivista. (Mestriner, 2005, p. 38). A competitividade está fortemente vinculada à qualidade do produto ou do serviço. "No Brasil da década de 90, qualidade do produto, por exemplo, era um critério decisivo para a grande maioria dos compradores. Nos dias atuais, está se tornando um critério qualificador, pois muitos compradores só consideram a possibilidade de comprar aqueles que possuem um grau mínimo de 
qualidade. A partir dessa qualificação, o comprador escolhe o produto que por meio dos seus critérios decisivos, como preço, ou prazo de entrega ou qualidade do atendimento ou outro. Nessa situação, as empresas devem investir apenas o suficiente para garantir esse patamar de qualidade e direcionar seus recursos e esforços para melhorar as características do produto e/ou da empresa naqueles aspectos que correspondem aos critérios decisivos do comprador.” (Contador, 2008, p.63).

Se a comodidade puder ser reconhecida como vantagem competitiva pode-se afirmar que comodidade é um campo de competição. Conceitualmente, campo da competição refere-se a uma vantagem competitiva de interesse do comprador, como qualidade e preço do produto. (Contador, 2008).

A obra de Contador (2008), em grande parte, ocupa-se do binômio campo-arma da competição. Contador foi o primeiro autor a fazer a abordagem até certo ponto original, pois divide a estratégia competitiva em campos da competição, relativos à estratégia de negócio, e em armas da competição, relativas às estratégias competitivas. Campo da competição diz respeito aos atributos que são de interesse direto do consumidor: custo, variedade de modelos, prazo, etc. Arma da competição é o meio que a empresa usa para alcançar vantagem competitiva no campo da competição escolhido.

Campo da competição nada mais é, portanto, do que o locus onde a empresa busca vantagem competitiva. Contador (2008) entende que "uma boa estratégia exige um ou dois campos principais e um ou dois coadjuvantes, que não sejam excludentes, como preço e prazo. Uma empresa não deve querer ser boa em tudo. Ela não precisa ser excelente em tudo: basta ter excelência naquelas armas que lhe dão vantagem competitiva nos campos escolhidos".

Augusto Guzzo Revista Acadêmica, 2013, № 12, 79-96
Por exemplo, competir em preço, segundo Contador (2008), é uma estratégia bastante adequada para pequenas empresas industriais que atuam em setores de tecnologia padronizada. Essas empresas têm, geralmente, uma vantagem competitiva importante em relação às grandes: sua estrutura organizacional menos complexa.

O presente trabalho levanta a questão se a comodidade pode ser reconhecida como campo de competição como são o preço, a qualidade e o prazo, por exemplo. Comodidade tem sido definida e medida por diversas disciplinas: é uma emoção positiva (Daniels, 2000; C.Storm \& Storm, 1987), um sentimento de se sentir "à vontade" (Simmons, 2001, p.199) ou associada à redução da ansiedade ou à redução desconforto emocional (Hill \& Garner, 1991, p.495). Comodidade é também associado a estabilidade (Cabanac, 2000) ou a "zona de conforto" (Rich \& Smith, 2000, p. 243). Não são estes aspectos relevantes para a presente pesquisa: o que se pretende investigar é até que ponto características específicas dos produtos ou serviços podem atrair clientes para a compra.

\section{Referencial Teórico}

Para se obter o conceito de comodidade pesquisou-se por artigos científicos nos repositórios de artigos científicos EBSCO e ProQuest utilizados pela disponibilidade de acesso. Os seguintes critérios foram configurados no software de busca e seleção dos dois repositórios: a) a opção "somente artigo acadêmico-científico" foi selecionada, b) a opção "somente com texto na integra" foi selecionada, c) revisado por especialistas; d) em data da publicação selecionou-se "todas as datas"; e d) com o termo "concepto of comfort" e "concept of comfortableness", presente no título e no resumo do artigo. A pesquisa foi realizada em março de 2012 e resultou em 24 artigos identificados. Após uma primeira 
leitura do tipo skimming, a seleção contemplou apenas o artigo de Spake, Beatty, Brockman e Crutchfield (2003): Consumer comfort in service relationships: Measurement and importance.

Os autores chamam a atenção para o fato que a importância da construção de um bom relacionamento com o cliente é bem documentada ainda que a importância da comodidade em serviços não tenha sido muito explorada. Com base nos resultados da sua pesquisa Spake et al. (2003) definiram comodidade do consumidor ("consumer comfort) como um estado psicológico no qual a ansiedade concernente a um serviço foi aliviada e o consumidor desfruta de tranquilidade mental e despreocupação. Tal definição é consistente com a literatura especialmente aquela que foca os aspectos psicológicos do comodidade: Sheth e Parvatiyar (1995) que consideram a redução de ansiedade, Hyland e Morse (1995) que consideram colocar o consumidor em tranquilidade; Gwinner, Gremler e Bitner (1998) que associam tranquilidade ao sentimento de segurança dado pelo fornecedor do serviço. Spake et al. (2003) testaram e confirmaram algumas hipóteses. Comodidade tem um impacto positivo, em relação ao serviço do fornecedor, sobre: (1) a confiança, (2) o comprometimento; (3) a voz ativa; e (4) a satisfação.

$\mathrm{Na}$ medida em que se procura investigar se comodidade pode expressar vantagem competitiva e, portanto, ser um campo de competição é necessário expressar este constructo de forma mais mensurável, capaz de "ser medido". Parte-se, portanto, do seguinte conceito: Comodidade é um atributo do produto ou serviço caracterizado por: (1) uma forma mais fácil de usar ou menor esforço para obter o benefício desejado; (2) ou menores barreiras de acesso ao produto ou serviço; (3) ou maior conforto sensitivo do ambiente de negociação ou (4) por nível maior de confiança (segurança psicológica) decorrente da sua obtenção. As propriedades de (1) maior ou melhor usabilidade do produto, de (2) maior facilidade no acesso ao produto ou serviço, de (3) maior conforto sensorial e de (4) maior confiança são relacionadas como características relevantes em produtos ou serviços como se pode ver abaixo.

Melhor usabilidade. Pela definição da International Organization for Standardization [ISO] (1999), usabilidade é a medida pela qual um produto pode ser usado por usuários específicos para alcançar objetivos específicos com efetividade, eficiência e satisfação em um contexto de uso específico.

A qualidade específica ou características do produto ou serviço podem proporcionar maior comodidade: o produto é mais fácil de usar, atende à necessidade ou desejo do consumidor mais rapidamente ou com menor esforço. Pequenas características implementadas em um produto podem proporcionar mais conforto ou benefício para o usuário, Perreault \& Mcacarthy (2002, p.181) relata: "A Oral B modificou sua escova de dentes convencional incluindo uma lista de cerdas coloridas que desaparece à medida que a escova vai sendo usada; assim, fica sabendo quando é hora de comprar uma escova nova", enquanto a concorrente: "A Colgate projetou novamente a escova de dentes com um cabo macio e cerdas angulares para retirar melhor o tártaro."

Para Kotler e Keller (2006, p. 371) o design é o fator que oferece uma constante vantagem competitiva de grande relevância: "trata-se do conjunto de características que afetam a aparência e o funcionamento do produto no que diz respeito à exigência dos clientes". Pode-se citar as embalagens tetra pack, que contribuíram para a conservação dos produtos. Por exemplo, o leite passou 
para em torno de noventa dias, muito superior, aos dois dias dos tradicionais saquinhos de polietileno utilizados anos atrás. Nogueira, Abreu, Paixão e Oliveira (2008) esclarecem que "ao longo dos anos, percebeu-se que o consumidor queria praticidade, sem que precisasse ir todo o dia comprar leite na padaria." Para eles, o consumidor "descobriu a facilidade deste tipo de embalagem que não precisa de refrigeração, e pode ser estocada". Dessa forma, houve uma aceitação por parte do consumidor brasileiro em geral e o mercado proporcionou uma nova realidade sobre o formato de embalagens, facilitando inclusive as questões relacionadas ao processo de distribuição.

Preferências deste tipo explicam a adoção de novas tecnologias e uma das explicações para tal comportamento concentra-se nos determinantes da aceitação individual de novas tecnologias, utilizando a intenção comportamental ou o próprio comportamento como variáveis dependentes (Davis, 1989; Davis, Bagozzi, \& Warshaw, 1989), de acordo com as teorias da Ação Racional (Fishbein \& Ajzen, 1975) e do Comportamento Planejado (Ajzen, 1985): os determinantes da adoção são definidos em termos de crenças, atitudes, normas subjetivas ou percepções sobre o controle do comportamento. Com base nestes autores é possível estabelecer as seguintes hipóteses:

$\mathrm{Ha}_{1}$ : Consumidores preferem um despertador a energia/bateria em vez de um despertador a corda para evitar o incômodo de ter que dar corda todos os dias, mesmo sabendo que é mais caro.

$\mathrm{Hb}_{1}$ : Consumidores para aquecerem um pequeno prato de alimentos preferem usar o micro-ondas em vez do fogão normal, ainda que saibam que o custo é maior.

Maior facilidade de acesso ao produto ou serviço: $\mathrm{O}$ acesso ao produto ou serviço é de grande valia, seja no ato de entrega, rápida ou dentro do prazo combinado, seja na disponibilização, ou acessibilidade dentro daquilo que atende o público alvo. Para Kotler e Keller (2006, p.372) “a entrega refere-se à qualidade com que o produto ou serviço é entregue ao cliente. Isso inclui velocidade, precisão e preocupação com o processo em si." Estes autores afirmam que os consumidores de hoje querem entregas rápidas, como pizza em 30 minutos, óculos em uma hora, filme revelado em uma hora, etc.

A facilidade que o cliente encontra para fazer um pedido à empresa encontra ajuda na internet que proporcionou uma grande revolução na capacidade de atender um grande número de clientes ao mesmo tempo e de forma rápida. "O show da banda de Mike Jagger no Hyde Park, em Londres, no próximo dia 06 de julho (2013), que deve reunir 65 mil pessoas teve todos os ingressos esgotados em apenas 3 minutos." (Urbano, 2013).

Os produtos de compra comparada, que são aqueles que o consumidor geralmente decide depois que compara com os produtos concorrentes, na medida em que possuem uma gama enorme de pequenas diferenças, são mais caros e o consumidor conviverá com eles mais tempo. Desta forma, é importante que a disponibilização seja facilitada para permitir incluir o produto ou a loja no rol de possibilidades de escolha. Para Boone e Kurtz (1998, p.252) "as novas lojas oferecendo uma variedade de produtos de compra comparada, precisam estar localizadas próximas a lojas do mesmo ramo, para que sejam incluídas nas explorações de compra".

Andersen (1973) considera que acesso é um dos elementos que abrange a entrada nos serviços e o recebimento de cuidados subsequentes. Penchansky e Thomas (1981) utilizam o termo acesso e centram esse conceito no grau de ajuste entre clientes e a 
empresa e identificam várias dimensões que compõem o conceito de acesso: disponibilidade (volume e tipo) de serviços em relação às necessidades; acessibilidade caracterizada pela adequação entre a distribuição geográfica dos serviços e dos clientes; acolhimento (accomodation), que representa a relação entre a forma como os serviços organizam-se para receber os clientes e a capacidade dos clientes para se adaptar a essa organização; capacidade de compra, definida pela relação entre formas de financiamento dos serviços e a possibilidade das pessoas de pagarem por esses serviços; e aceitabilidade, que representa as atitudes das pessoas e dos profissionais da empresa em relação às características e práticas de cada um.

Com base nestas considerações é possível estabelecer as seguintes hipóteses:

$\mathrm{Hc}_{1}$ : O consumidor opta por comprar um produto perto de sua casa, para evitar andar, mesmo pagando um pouco mais caro.

$\mathrm{Hd}_{1}$ : O consumidor, mesmo que pague a mais, prefere os estabelecimentos que oferecem formas de recebimento por meio do cartão de crédito às que aceitam somente dinheiro ou cheque.

Maior conforto sensorial: Originalmente, a palavra conforto deriva do vocabulário de origem latina confortare, com o significado de fortificar, consolar (Schmid, 2005). Para Slater (1986), o conforto é um “estado agradável de harmonia fisiológica, psicológica e física entre o ser humano e o ambiente". De acordo com Lipovetsky (2007, p. 198), assiste-se, "desde os anos 90, ao desenvolvimento de um design do tipo polissensorial que tem por fim otimizar a dimensão sensorial dos produtos criando impressões de conforto e sensações de prazer".
O conforto é uma das principais características avaliadas pelo consumidor no momento da decisão pela compra de um produto. Isto se deve ao comportamento do homem moderno, ao estilo de vida agitado que, com jornadas de trabalho mais longas, faz com que haja uma crescente busca pelo bem-estar durante todo o dia. (Alencar \& Boueri, 2012).

O ambiente de comercialização ou da prestação de serviço deve proporcionar ao cliente o conforto adequado, a organização, decoração, iluminação, limpeza, aspectos visuais e auditivos. Tais aspectos podem contribuir para a vivência e percepção da qualidade e do carinho com que o produto ou serviço está cercado, proporcionando integração sensorial e momento favorável aos clientes ali presentes. Constitui marco teórico da influência do ambiente de negócios no comportamento dos clientes o artigo de Kotler (1973), do qual emergiu o conceito "atmosfera de loja", compreendendo todo o conjunto de sentimentos do consumidor relativos à personalidade da loja, desenvolvidos a partir de recursos que influenciam visão, olfato e outras propriedades sensitivas dos clientes.

Segundo Lane (2002, p.4) a integração sensorial é um processo neurológico que organiza a sensação do nosso corpo e do ambiente e torna possível a utilização do corpo dentro do contexto ambiental.

Os aspectos espaciais e temporais das informações recebidas de diferentes modalidades sensoriais são interpretados, associados e unificados; sendo então emitida uma resposta de acordo com as exigências do meio. O sistema nervoso coordena todas as atividades orgânicas, integra sensações e ideias, conjuga fenômenos da consciência e adapta o organismo às condições do momento. (Watanabe, 2000, p.87). 
"O comportamento dos compradores tem incentivado a tendência varejista de se criarem ambientes que entretenham e instruam os consumidores, elevando a importância da atmosfera das lojas." (Boone \& Kurtz, 1995 p. 356).

Considerando o contexto ambiental de acesso, se pode estabelecer as seguintes hipóteses:

$\mathrm{He}_{1}$ : O consumidor prefere os Shoppings Centers por causa do conforto das instalações, mesmo sabendo que os produtos são mais caros.

$\mathrm{Hf}_{1}$ : O consumidor, mesmo pagando o combustível mais caro, dá preferência a posto de gasolina que leve ao carro a máquina de cartão de crédito, evitando que ele tenha de sair do carro para pagar.

Maior confiança ou segurança psicológica: Para Gosling e Gonçalves (2002) a confiança é um construto bastante difundido na literatura do marketing de relacionamento. Especificamente nos serviços, a confiança é primordial, principalmente dada a intangibilidade dos mesmos, como salientam Morgan e Hunt (1994) e Berry (2000, p.163). A segurança psicológica pode ser definida como um "clima de equipa caracterizado pela confiança e respeito mútuo no qual as pessoas se sentem confortáveis a serem elas próprias." (Edmondson, 1999, p. 354).

A empresa é testada pelo consumidor e se estabelece a relação de confiança que pode culminar na fidelização do cliente. Contador (2008) ressalta que, do ponto de vista prático, uma garantia de 4 ou 5 anos não tem muita relevância se o consumidor troca de carro a cada 2 anos. Entretanto, essa característica poderá representar para o cliente mais confiança no produto que tem a maior garantia. A confiança do cliente pode ser entendida como: "as expectativas, mantidas pelo consumidor, de que o provedor de serviço é responsável e pode ser confiável na entrega de suas promessas". (Sirdeshmukh, Singh \& Sabol, 2002, p. 17).

A satisfação pós-compra (ou inicial) tem sido considerada a mediadora principal entre crenças anteriores à compra e estruturas cognitivas pós-compra, comunicações e comportamento de recompra. (Westbrook, 1987). Santos e Fernandes (2008) afirmam que a confiança do consumidor no contexto de serviços tem sido estudada como um conceito bidimensional, em que uma dimensão diz respeito à confiança nos funcionários da linha de frente e a outra se relaciona às políticas da empresa prestadora de serviços. Kotler e Keller (2006, p.371) relatam que: "em geral os compradores pagam um preço premium por produtos mais confiáveis. O cliente a partir de diversos sinais faz essa mensuração, que certamente influencia sua tomada de decisão.

Com base nas considerações acima é possível estabelecer as seguintes hipóteses:

$\mathrm{Hg}_{1}$ : $\mathrm{O}$ consumidor, se necessitar de um advogado, tem na indicação de um amigo um aspecto relevante na hora da escolha, independente do custo dos serviços desse advogado.

$\mathrm{Hh}_{1}$ : $\mathrm{O}$ consumidor, entre duas empresas de mecânica de autos fica com a que lhe transmite mais confiança, ainda que com um preço ligeiramente maior.

\section{Procedimentos operacionais da pesquisa}

A pesquisa, de acordo com Babbie (1999), é uma survey. Ainda é possível classificar a presente pesquisa como sendo interdisciplinar, subjetiva (opinativa e atitudinal); de dados primários (oriundos dos questionários aplicados) e descritiva. 
Os pesquisadores abordaram 220 pessoas à saída de lojas em quatro Shoppings Centers da capital do Estado de São Paulo, que responderam a um questionário escala Likert (1-5), pelo que a amostra pode ser considerada de conveniência. Depurados os questionários preenchidos incorretamente ou com omissões, a amostra final resultou em 214 questionários.

A escala aplicada foi construída e validada seguindo-se o procedimento descrito em Baquero (1974):

1. Inicialmente foi construída uma escala $\mathrm{E}_{0}$ com 24 proposições, seis para cada fator. Tal escala foi submetida a quatro especialistas em Marketing (Mestres e Doutores com trabalhos publicados na área), sendo descartadas duas proposições desse processo de validação do conteúdo, surgindo assim a escala $\mathrm{E}_{1}$ com 22 proposições..

2. A escala $E_{1}$ foi então aplicada a dois grupos, cada um com dez sujeitos. $\mathrm{O}$ primeiro grupo com sujeitos que notoriamente se dispunham a pagar pela comodidade e o segundo grupo com pessoas mais refratárias a isso. Foram eliminadas quatro proposições que não apresentaram poder discriminatório, ou seja: as diferenças das somas das respostas dadas pelos dois grupos não superavam 10 pontos, o que significava que a proposição não conseguia distinguir entre um respondente pró- comodidade de outro que não o fosse. Originou-se assim a escala $\mathrm{E}_{2}$ com 18 proposições.

3. A escala $E_{2}$ foi submetida ao teste de análise de confiabilidade por meio do software SPSS 17.0 utilizando a função Reliability Analysis. Inicialmente, a escala com 18 proposições, obteve o valor $\alpha$ de Cronbach de 0,651. De forma geral, considera-se que um bom valor do $\alpha$ é pelo menos 0,70. Esta regra deve ser aplicada com prudência uma vez que, o grau adequado de fidedignidade depende da utilização do instrumento. Pereira (1999, p.87) afirma que para interpretar o $\alpha$ de Cronbach, pode-se entendê-lo como um coeficiente de correlação ao quadrado $\left(\mathrm{R}^{2}\right)$ com uma suposta medida real do fenômeno. Desta forma, com o intuito de elevar o valor de $\alpha$ de Cronbach foram removidas mais três proposições obtendo-se então um valor de 0,711 como mostra a figura 1.

Pode-se afirmar, desta forma, que o instrumento de coleta de dados está de acordo com Hair, Rolph, Tatham e Black (1998) e Bagozzi e Phillips (1991). O conteúdo da escala aplicada com 15 proposições é exibido no Apêndice. Além das proposições mostradas foram solicitados aos respondentes outros dados tais como: idade, gênero, escolaridade e área de atividade econômica.

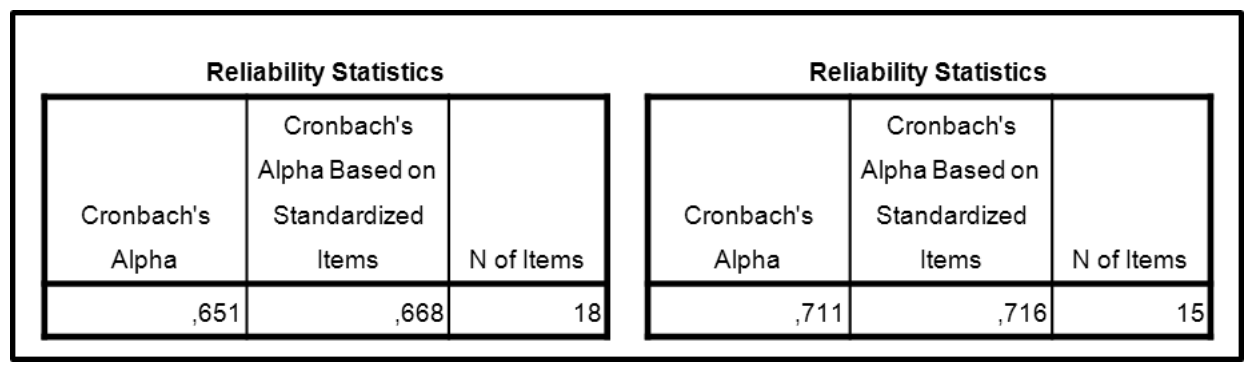

SANCHES, C., SOUZA, H.G. e PAIXÂO, M.R..: Um Estudo da Comodidade Como Característica 
Figura 1: $\alpha$ de Cronbach (1951) no teste de confiabilidade da Escala.

A coleta de dados ocorreu entre os dias 9 e 17 de fevereiro de 2013. A pesquisa fez uso de questionário tipo Likert, especialmente construído e validado. A escala Likert, como qualquer outra escala, fundamenta-se no estabelecimento de premissas de relação entre atributos de um objeto e uma representação simbólica desses atributos. Pereira (1999) destaca que o sucesso da escala Likert deve residir no fato de que "ela tem a sensibilidade de recuperar conceitos aristotélicos da manifestação de qualidades: reconhece a oposição entre contrários; reconhece gradiente e reconhece a situação intermediária". Com efeito, a escala Likert solicita do respondente que a uma dada afirmação expresse o seu grau de concordância, geralmente do tipo: a) discordo totalmente; b) discordo; c) indiferente; d) concordo e e) concordo totalmente. A estas categorias se dá o nome de diferencial semântico.

Foi feita uma pesquisa de forma a estabelecer um conjunto inicial de proposições destinadas a avaliar se os respondentes estariam dispostos a pagar monetariamente pela comodidade, estando esta expressa por quatro fatores:

(i) comodidade uma forma mais fácil de usar; (ii) comodidade como menores barreiras de acesso;

(iii) comodidade como maior conforto sensitivo ou

(iv) comodidade como maior nível de segurança psicológica.

Para testar as hipóteses e analisar os resultados se fez uso, fundamentalmente de testes não-paramétricos, e, sempre que possível, desde que as amostras tivessem passado no teste de normalidade, testes paramétricos.

\section{Resultados}

Inicialmente foram feitas estatísticas descritivas. Dos 214 respondentes 57,01\% (122) trabalham em serviços ou comércio, $17,75 \%$ (38) na indústria e $25,23 \%$ (54) não trabalham ou não declararam ocupação. A proporção das mulheres na amostra foi de $41,12 \%$ (88). A maioria dos respondentes tem de 6 a 10 anos de estudo e não há diferença significativa na forma de distribuição dos anos de instrução por gênero, como mostra a tabela 1 .

Tabela 1: Homens e mulheres respondentes não se diferenciam por instrução

\begin{tabular}{c|c|c|c|c|c|c}
\hline Masculino & $\%$ & Feminino & $\%$ & Total & $\%$ & Anos de instrução \\
\hline 7 & 5.56 & 5 & 5.68 & $\mathbf{1 2}$ & $\mathbf{5 . 6 1}$ & 0 ou não declarado \\
\hline 21 & 16.67 & 12 & 13.64 & $\mathbf{3 3}$ & $\mathbf{1 5 . 4 2}$ & 1 a 5 \\
\hline 70 & 55.56 & 52 & 59.09 & $\mathbf{1 2 2}$ & $\mathbf{5 7 . 0 1}$ & 6 a 10 \\
\hline 28 & 22.22 & 19 & 21.59 & $\mathbf{4 7}$ & $\mathbf{2 1 . 9 6}$ & $\geq 11$ \\
\hline 126 & 100.00 & 88 & 100.00 & $\mathbf{2 1 4}$ & $\mathbf{1 0 0 . 0 0}$ & Total \\
\hline
\end{tabular}


O grau de aderência dos respondentes a cada proposição foi calculado por um oscilador que mostra a força relativa entre a discordância (respostas em DT e D) e a concordância (respostas em C e CT). As respostas em I (indiferentes) foram desconsideradas. A coluna 11 da tabela 2 mostra o grau de aderência dos respondentes a cada proposição. O oscilador que exprime o grau de aderência (GA) segue a proposta de Wilder (1981) e gera um número entre um mínimo de zero e um máximo de 100 . Níveis acima de 50 indicam tendência concordante e, abaixo, tendência discordante. A fórmula geral é:

$$
G A=100-\left(\frac{100}{\frac{C}{D}+1}\right)
$$

onde GA é o grau de aderência; $C$ indica a quantidade ou proporção de respostas concordantes, e D indica a quantidade ou proporção de respostas discordantes. Excetuando as proposições (na tabela 2) 8, $11,1,14,4,7$ e 9 com $G A \leq 50$, as demais oito proposições apresentam concordância.

Há diferença significativa pelo menos ao nível de significância de 0,05 entre discordantes e concordantes, exceto no que se refere às proposições 2 'Prefiro comprar em lojas com estacionamento, mesmo que eu pague por esse estacionamento'; e 4 'Para resolver problemas de menor importância, prefiro usar e pagar a ligação telefônica em vez de mandar e-mail'. Nestas duas proposições os $\mathrm{p}$-value observados foram respectivamente 0,2836 e 1,00, o que significa que não há diferença significativa entre respondentes concordantes e discordantes.

Um fator é expresso por um conjunto de proposições e a escala considera quatro fatores designados por: acesso, confiança, conforto e uso. Considerando fator a fator, excetuando 'conforto físico', os respondentes estão dispostos a pagar pela comodidade. Todas as proposições relacionadas a 'conforto' (1, 14, 4, 7, e 9) possuem grau de aderência $\leq 50$, o que mostra claramente que os pesquisados não estão dispostos a pagar por tal comodidade.

Por outro lado, os pesquisados parecem dispostos a pagar por 'uma forma mais fácil de usar ou menor esforço para obter o benefício desejado' $(\mathrm{p}<0,0001)$, 'menores barreiras de acesso ao produto ou serviço' ( $\mathrm{p}<0,0001)$, 'nível maior de segurança psicológica (confiança)’ ( $p<0,0001)$.

Foram rejeitadas as hipóteses He1 e Hf1 ao nível de significância 0,05 :

Maior conforto sensorial:

He1: O consumidor prefere os Shoppings Centers por causa do conforto das instalações, mesmo sabendo que os produtos são mais caros.

Hf1: O consumidor, mesmo pagando o combustível mais caro, dá preferência a posto de gasolina que leve ao carro a máquina de cartão de crédito, evitando que ele tenha de sair do carro para pagar. 
Tabela 2: Aderência dos respondentes às proposições e aos fatores

\begin{tabular}{|c|c|c|c|c|c|c|c|c|c|c|c|c|c|}
\hline 1 & 2 & 3 & 4 & 5 & 6 & 7 & 8 & 9 & 10 & 11 & 12 & 13 & 14 \\
\hline$F$ & $\mathrm{H}$ & $\mathrm{P}$ & PROPOSIÇÕES & DT & D & I & $\mathrm{C}$ & CT & Disc & Conc & $\mathrm{GA}$ & Totais & p-value \\
\hline \multirow{5}{*}{ 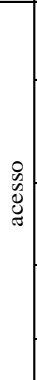 } & $\mathrm{Hc}$ & 6 & $\begin{array}{l}\text { Já optei por comprar um produto perto de minha casa, para evitar andar, mesmo } \\
\text { pagando um pouco mais caro. }\end{array}$ & 18 & 32 & 22 & 110 & 32 & 50 & 142 & 73.96 & 192 & $<0,0001$ \\
\hline & $\mathrm{Hd}$ & 12 & $\begin{array}{l}\text { Mesmo que pague a mais, prefiro os estabelecimentos que oferecem formas de } \\
\text { recebimento por meio do meu cartão de crédito às que aceitam somente dinheiro } \\
\text { ou cheque. }\end{array}$ & 25 & 25 & 57 & 76 & 31 & 50 & 107 & 68.15 & 157 & $<0,0001$ \\
\hline & & 2 & $\begin{array}{l}\text { Prefiro comprar em lojas com estacionamento, mesmo que eu pague por esse } \\
\text { estacionamento }\end{array}$ & 29 & 38 & 67 & 55 & 25 & 67 & 80 & 54.42 & 147 & 0,2836 \\
\hline & & 8 & $\begin{array}{l}\text { Mesmo gastando um valor um pouco maior, compro pela internet pela facilidade } \\
\text { de fazer a compra, já que não preciso me deslocar até ao ponto de venda. }\end{array}$ & 45 & 57 & 46 & 43 & 23 & 102 & 66 & 39.29 & 168 & 0,0055 \\
\hline & & & Fator: Acesso & 117 & 152 & 192 & 284 & 111 & 269 & 395 & 59.49 & 664 & $<0,0001$ \\
\hline \multirow{4}{*}{ 胥 } & $\mathrm{Hg}$ & 3 & $\begin{array}{l}\text { Se necessitar de um advogado, a indicação de um amigo é um aspecto relevante } \\
\text { na hora da escolha, independente do custo dos serviços desse advogado. }\end{array}$ & 10 & 35 & 34 & 100 & 35 & 45 & 135 & 75.00 & 180 & $<0,0001$ \\
\hline & $\mathrm{Hh}$ & 13 & $\begin{array}{l}\text { Entre duas empresas de mecânica de autos fico coma que me transmite mais } \\
\text { confiança, ainda que com um preço ligeiramente maior }\end{array}$ & 7 & 14 & 18 & 114 & 61 & 21 & 175 & 89.29 & 196 & $<0,0001$ \\
\hline & & 11 & $\begin{array}{l}\text { Estou disposto a pagar a taxa de garantia para estender o tempo dos serviços } \\
\text { pós-venda pois isso é um elemento importante para reforçar a confiança no } \\
\text { produto ou serviço. }\end{array}$ & 50 & 59 & 46 & 43 & 16 & 109 & 59 & 35.12 & 168 & $<0,0001$ \\
\hline & & & Fator: Confiança & 67 & 108 & 98 & 257 & 112 & 175 & 369 & 67.83 & 544 & $<0,0001$ \\
\hline \multirow{6}{*}{\begin{tabular}{l|l}
$\stackrel{0}{0}$ \\
$\stackrel{0}{0}$ \\
$\stackrel{0}{0}$ \\
0
\end{tabular}} & $\mathrm{He}^{*}$ & 1 & $\begin{array}{l}\text { Quando vou às compras prefiro os Shoppings Centers por causa do conforto das } \\
\text { instalações, mesmo sabendo que os produtos são mais caros }\end{array}$ & 46 & 59 & 55 & 35 & 19 & 105 & 54 & 33.96 & 159 & $<0,0001$ \\
\hline & Hf* & 14 & $\begin{array}{l}\text { Mesmo pagando o combustível mais caro, dou preferência a posto de gasolina } \\
\text { que me traga ao carro a máquina de cartão de crédito, evitando que eu tenha que } \\
\text { sair do carro para pagar. }\end{array}$ & 56 & 61 & 51 & 34 & 12 & 117 & 46 & 28.22 & 163 & $<0,0001$ \\
\hline & & 4 & $\begin{array}{l}\text { Para resolver problemas de menor importância, prefiro usar e pagar a ligação } \\
\text { telefônica em vez de mandar e-mail }\end{array}$ & 30 & 55 & 44 & 59 & 26 & 85 & 85 & 50.00 & 170 & 1,00 \\
\hline & & 7 & $\begin{array}{l}\text { Quando vou às compras prefiro as lojas mais bem decoradas, mesmo que o } \\
\text { produto seja um pouco mais caro }\end{array}$ & 51 & 69 & 64 & 26 & 4 & 120 & 30 & 20.00 & 150 & $<0,0001$ \\
\hline & & 9 & $\begin{array}{l}\text { Em datas festivas, como Natal ou Dia das Mães, prefiro as lojas comboa } \\
\text { decoração temática, mesmo que o produto seja umpouco mais caro }\end{array}$ & 59 & 79 & 54 & 18 & 4 & 138 & 22 & 13.75 & 160 & $<0,0001$ \\
\hline & & & Fator : Conforto & 242 & 323 & 268 & 172 & 65 & 565 & 237 & 29.55 & 802 & $<0,0001$ \\
\hline \multirow{5}{*}{$\begin{array}{l}\mathscr{0} \\
\Rightarrow\end{array}$} & $\mathrm{Ha}$ & 5 & $\begin{array}{l}\text { Prefiro um despertador a energia/bateria em vez de um despertador a corda para } \\
\text { evitar o incômodo de ter que dar corda todos os dias mesmo sabendo que é mais } \\
\text { caro. }\end{array}$ & 28 & 32 & 45 & 61 & 48 & 60 & 109 & 64.50 & 169 & $<0,0001$ \\
\hline & $\mathrm{Hb}$ & 15 & $\begin{array}{l}\text { Para aquecer um pequeno prato de alimentos prefiro usar o micro-ondas em vez } \\
\text { do fogão normal ainda que saiba que o custo é maior }\end{array}$ & 13 & 20 & 35 & 81 & 65 & 33 & 146 & 81.56 & 179 & $<0,0001$ \\
\hline & & 10 & $\begin{array}{l}\text { Mesmo sendo mais caro, prefiro comprar um GPS para o carro a qualquer Guia } \\
\text { impresso }\end{array}$ & 29 & 38 & 53 & 59 & 35 & 67 & 94 & 58.39 & 161 & 0.0333 \\
\hline & & & Fator: Uso & 70 & 90 & 133 & 201 & 148 & 160 & 349 & 68.57 & 509 & $<0,0001$ \\
\hline & & & Todos os fatores & 496 & 673 & 691 & 914 & 436 & 1169 & 1350 & 53.59 & 2519 & 0.0003 \\
\hline
\end{tabular}

Nota: Coluna 1: fator de comodidade que é representado por algumas proposições; Col. 2: Hipótese; Col.3: Número na proposição na Escala; Col.4: Conteúdo da proposição; Col. 5 a 9: Diferencial semântico: DT-Discordo totalmente; D:Discordo; I- Indiferente; C:Concordo; CT-Concordo totalmente; Col.10: total de respostas discordantes (DT+D) dadas à proposição; Col.11: total de respostas concordantes $(\mathrm{C}+\mathrm{CT})$ dadas à proposição; Col.12: Grau de aderência calculada pela fórmula de Wilder (1981); Col. 13: Soma dos discordantes e concordantes; Col. 14: p-value do teste $\chi^{2}$ para verificar se há diferença significativa entre discordantes e concordantes. Fonte: Autores.

Não foram rejeitadas as demais hipóteses, ao nível de significância 0,01:
Melhor usabilidade:

Ha1: Consumidores preferem um despertador a energia/bateria em vez 
de um despertador a corda para evitar o incômodo de ter que dar corda todos os dias mesmo sabendo que é mais caro.

Hb1: Consumidores para aquecerem um pequeno prato de alimentos preferem usar o micro-ondas em vez do fogão normal ainda que saibam que $o$ custo é maior.

Maior facilidade de acesso ao produto ou serviço:

Hc1: O consumidor opta por comprar um produto perto de sua casa, para evitar andar, mesmo pagando um pouco mais caro.

Hd1: O consumidor, mesmo que pague a mais, prefere os estabelecimentos que oferecem formas de recebimento por meio do cartão de crédito às que aceitam somente dinheiro ou cheque.

Maior confiança ou segurança psicológica:

Hg1: O consumidor, se necessitar de um advogado, tem na indicação de um amigo um aspecto relevante na hora da escolha, independente do custo dos serviços desse advogado.

Hh1: O consumidor, entre duas empresas de mecânica de autos fica com a que lhe transmite mais confiança, ainda que com um preço ligeiramente maior.

De forma geral, os respondentes tendem a ser concordantes em pagar o custo da comodidade, como mostra a última linha da tabela 2: $G A=53,59$. A tabela 3 confirma isso ao mostrar que os 214 respondentes apresentam uma média de aderência superior a 50. Neste caso, o valor apresentado é o da média do grau de aderência de cada respondente. A discrepância do valor da tabela $2(53,59)$ e o da tabela $3(54,36)$ é decorrente dos arredondamentos feitos durante a análise.

Dos 214 respondentes 81 tinham grau de aderência discordante e 128 grau de aderência concordante. Cinco dos respondentes apresentaram grau de concordância igual a 50, não constando da análise da tabela 3 .

Tabela 3: Aderência média dos respondentes

\section{Descriptive Statistics: T; D; C}

\begin{tabular}{|c|c|c|c|c|c|c|c|c|}
\hline & Total & & & & & & & \\
\hline Variable & Count & Mean & StDev & Minimum & Q1 & Median & Q3 & Maximum \\
\hline $\mathrm{T}$ & 214 & 54.36 & 20.54 & 6.67 & 41.67 & 57.14 & 66.67 & 100.00 \\
\hline $\mathrm{D}$ & 81 & 32.89 & 12.18 & 6.67 & 26.67 & 36.36 & 42.86 & 46.67 \\
\hline $\mathrm{C}$ & 128 & 68.55 & 11.11 & 53.33 & 60.00 & 66.66 & 73.33 & 100.00 \\
\hline
\end{tabular}

Nota: Os dados das variáveis possuem distribuição que não difere significativamente da distribuição normal de acordo com o teste D’Agostini (desvio = 0,2817 para valores críticos a 5\%: 0,2272 a 0,2851). Coluna Variable: T=total de casos; $\mathrm{D}=$ respondentes discordantes $(\mathrm{GA}<50)$; $\mathrm{C}=$ respondentes concordantes $(\mathrm{GA}>50)$. Omitidos os casos indiferentes $(\mathrm{GA}=50)$. Count: quantidade de casos; Mean: média do grau de aderência dos respondentes; StDev: desvio padrão; Minimum: menor valor observado; Q1: primeiro quartil; Median: Mediana; Q3: terceiro quartil; Maximum: valor máximo observado. Fonte: Autores.

Foi feito um teste binomial para duas proporções, mostrado na figura 2 , testando se os 128 casos de concordância representavam uma proporção $(0,5981)$ significativamente maior do que a que se teria por mero acaso
$(0,50)$. O resultado mostrou que a diferença é significativa com $\mathrm{p}=0,0207$. De forma geral, portanto, os respondentes tendem a ser concordantes em pagar a comodidade. 


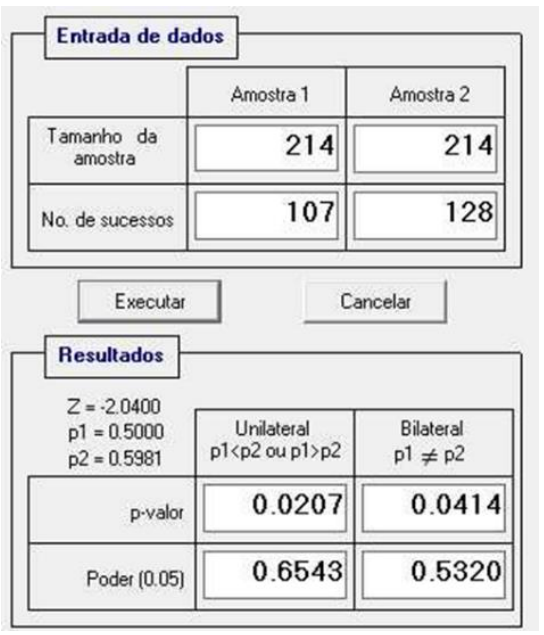

Figura 2: Teste binomial para duas proporções

\section{Conclusões e Recomendações}

Os resultados mostram que as características de comodidade residentes nos produtos ou serviços servem de atratividade para a compra, principalmente quando se trata de atributos do produto ou serviço caracterizados por:

uma forma mais fácil de usar ou menor esforço para obter o benefício desejado, concordando com Spake et al. (2003) e Hill e Garner (1991). Há uma grande concordância dos pesquisados com relação a pagar pela comodidade que produtos inovativos tendem a oferecer: Estão dispostos a pagar a mais por um despertador a energia/bateria em vez de um despertador a corda para evitar o incômodo de ter que dar corda todos os dias, mesmo sabendo que é mais caro $(\mathrm{GA}=64,5)$; estão dispostos a pagar mais por usar novas tecnologias como 'aquecer um pequeno prato de alimentos no micro-ondas em vez do fogão normal' $(\mathrm{GA}=81,56)$; ou 'comprar um GPS para o carro a qualquer Guia impresso, ainda que seja mais caro' $(\mathrm{GA}=58,39)$;

ou menores barreiras de acesso ao produto ou serviço o que está de acordo com Dabholkar, Shepherd e Thorpe (2000) que exploraram especialmente a comodidade dos clientes nas relações de serviço. Os pesquisados estão dispostos de forma geral a pagar por facilidade de acesso ao produto ou serviço: preferem 'comprar um produto perto de casa'(GA=76,96); 'estabelecimentos que oferecem formas de recebimento diversas' $(\mathrm{GA}=68,15)$; e usar 'lojas com estacionamento'(GA=54,42), mesmo que paguem por isso. Entretanto, não concordam em 'comprar pela internet pela facilidade de fazer a compra, já que não precisa se deslocar até ao ponto de venda'(GA=39,29); e

por nível maior de confiança (segurança psicológica) decorrente da sua obtenção: o que está de acordo com Scitovsky (1992) que abordou a questão do conforto psicológico de clientes em relação a provedores de serviço ou com Campion (1988), Dunn (1977) e Fordham (2000) que discutiram diversos aspectos do conforto decorrente do ambiente da negociação. Curiosamente a proposição "estou disposto a pagar a taxa de garantia para estender o tempo dos serviços pós-venda pois isso é um elemento importante para reforçar a confiança no produto ou serviço" teve aderência baixa $(\mathrm{GA}=35,12)$, o que confronta com os achados de Mc Dougall e Levesque (1988) que atribuem alto nível de conforto a este tipo de serviço. É possível que a garantia ampliada amplie a confiança no produto, mas não é algo que o usuário esteja disposto a pagar. Os pesquisados, entretanto, dispõe-se a pagar um advogado $(\mathrm{GA}=75,00)$ ou um mecânico $(\mathrm{GA}=89,29)$ se deles tiverem referências de seriedade e 
competência que lhes transmita confiança.

Ficou claro na análise que os respondentes não parecem dispostos a pagar por maior conforto sensitivo do ambiente de negociação: não estão dispostos a pagar o conforto das instalações dos Shoppings Centers $(G A=33.96)$; a decoração das lojas $(G A=20.00)$, mesmo a decoração temática $(\mathrm{GA}=13.75)$. Também não querem pagar o combustível mais caro em troca de pequeno conforto físico $(\mathrm{GA}=28.22)$.

No caso de resolver problemas de menor importância, ficam indecisos entre usar e pagar a ligação telefônica ou mandar email $(\mathrm{GA}=50.00)$.

Auliciems (1972) chama atenção para a questão da atmosfera no ambiente de negociação, estabelecendo uma associação positiva que não se verificou na pesquisa. Isso parece mostrar que o problema relacionado à importância do conforto físico para os usuários é complexo. Rheingantz (2001) já chamava a atenção para essa dificuldade ao afirmar que o estudo da percepção ambiental é um processo cognitivo que lida com as conformações subjetivas, imagens, impressões e crenças que as pessoas possuem do meio ambiente. Este processo cognitivo está sujeito a "filtros" socioculturais, categorias e sistemas resultantes do processo de socialização do indivíduo e a "filtros psicológicos" dependentes do sistema interpretativo pessoal, de valores e de expectativas de cada pessoa.

Como conclusão geral pode-se afirmar que os respondentes tendem a ser concordantes em pagar o custo da comodidade, o que é mais um ponto a favor de 'comodidade' ser reconhecida como campo da competição, ampliando possivelmente os campos apontados por Contador (2008). A comodidade pode ser reconhecida, portanto, como campo de competição como são o preço, a qualidade e o prazo por exemplo. Mas a pesquisa não pode ser considerada conclusiva porquanto há uma área do constructo que é negada nesse aspecto; os respondentes não parecem dispostos a pagar por maior conforto sensitivo.

A pesquisa deixa mais dúvidas do que respostas: por um lado mostra que os pesquisados aceitam pagar pela comodidade, mas não por qualquer aspecto considerado. $\mathrm{O}$ que leva o conforto físico a não ser tão considerado? É uma questão que fica para futuras pesquisas.

Espera-se que a presente pesquisa tenha contribuído para o estudo da comodidade, especialmente no campo do Marketing e para o estudo dos determinantes individuais do comportamento do consumidor, especialmente no que se refere ao processo de decisão de compra.

Esta pesquisa amplia a base dos estudos relacionados com o constructo 'comodidade' e chama a atenção para aspectos da teoria de Campos e Armas da Competição, descortinando a sua importância como potencial característica do produto ou serviço capaz de representar vantagem competitiva.

Embora estes sejam alguns pontos importantes a destacar, cabe lembrar, na visão de Selltiz et al. (1975), que a relação entre a teoria e a pesquisa é sinérgica pois amplia a compreensão dos fatos, ao mesmo tempo que permite a geração de novas teorias.

\section{Referências Bibliográficas}

1. Ajzen, I. (1985). From intentions to actions: a theory of planned behaviour. In J. Kuhl \& J. Beckman (Eds.). Action-control: 
from cognition to behaviour. Heidelberg: Springer.

2. Alencar, C. O.C., \& Boueri, J . (2012). O conforto no vestuário: uma análise da relação entre conforto e moda. VIII Colóquio de Moda.

3. Andersen R.M., \& Newman J.F. (1973). Societal and individual determinants of medical care utilization in the United States. Milbank Mem Fund, 51(1), 95-124.

4. Auliciems, A. (1972). The atmospheric environement: a study of comfort and performance. Toronto, Canada: University of Toronto Press.

5. Babbie, E. (1999). Métodos de pesquisas de survey. Belo Horizonte, UFMG.

6. Bagozzi, R.P., \& Phillips, L.W. (1991). Assessing construct validity. In: Organizational research. Administrative Science Quaterly, Cornell, 36,421-58.

7. Berry, L. (2000). Relationship marketing of services: growing interest, emerging perspectives. In: J.N., Sheth, \& A. Parvatiya A. (eds.). Handbook of Relationship Marketing. London: Sage.

8. Boone, L., \& Kurtz, D. (1998). Marketing Contemporâneo (8a ed.). Rio de Janeiro: LTC.

9. Cabanac, M. (2000). Pleasure and joy, and their role in human life. In: ClementsCroome, Dereck (ed.). Creating the productive workplace. London: E\&FN Spon.
Campion, M. A. (1988). Interdisciplinary Approaches to Job Design: a Constructive Replication with Extensions. Journal of Applied Psychology, 73(3), 467-79.

10. Contador, J. C. (2008). Campos e Armas da Competição. São Paulo: Saint Paul. Cronbach, L. J. Coefficient alpha and the internal structure of the tests. Psychometrika, Springer New York, 16(3), 297-334.

11. Dabholkar, P. A., Shepherd, D., \& Thorpe, D. I. (2000). A comprehensive framework for service quality: an investigation of critical conceptual and measurement issues through a longitudinal study. Journal of Retailing, 76(2), 139-73.

12. Daniels, K. (2000). Measures of five aspects of affective well-being at work. Human Relations, 53(2), 275-94.

13. Davis, F. D. (1989). Perceived usefulness, perceived ease of use, and user acceptance of computer technology. MIS Quarterly, 13(3), 319-340.

14. Davis, F. D., Bagozzi, R. P., \& Warshaw, P. R. (1989). User acceptance of computer technology: a comparison of two theoretical models. Management Science, 35(8), 9821003.

15. Dunn, J. (1977). Distress and comfort. Cambridge. MA: Harvard University Press. Fishbein, M., \& Ajzen, I. (1975). Belief, attitude, intention, and behavior. An 
introduction to theory and research. Reading, MA: Addison-Wesley.

16. Fordham, M. (2000). A broad definition of comfort as an aid to meeting commitments on carbon dioxide reduction. In: D. Clements-Croome (ed.). Creating the productive workplace. London: E\&FN Spon. 17. Gosling, M., \& Gonçalves, C.A. (2002, setembro). Estratégias de relacionamentos em bancos: um estudo empírico. Anais do Encontro Nacional da Associação Nacional de Pós-Graduação e Pesquisa em Administração. Rio de Janeiro, RJ, Brasil, 26. 18. Gwinner, K.P., Gremler, D.D., \& Bitner, M.J. (1998). Relational benefits in services industries: the customer's perspective. Journal of the Academy of Marketing Science. 26(2), 101-14.

19. Hair, J.R., Rolph, E, Tatham, R.L., \& Black, W.C. (1998). Multivariate Data Analysis (5a ed.). New Jersey: Prentice Hall. 20. Hill, C.J., \& Garner, S.J. (1991). Factors influencing physician choice. Hospital \& Health Services Administration. 36(4), 491503.

21. Hyland, L., Morse, J.M. (1995).

Orchestrating comfort: the role of funeral directors. Death Studies, 19(5), 453-74.

International Organization for Standardization. (2011) International Organization for Standardization.
Kotler, P. (1973). Atmospherics as a marketing tool. Journal of Retailing, 49, 4864.

22. Kotler, P., \& Keller, K. (2006). Administração de marketing (12a ed.). São Paulo: Pearson Prentice Hall.

23. Lane, S. J. (2002). Sensory integration: Theory and practice ( $3 \mathrm{a}$ ed). Philadelphia: F.A. Davis.

24. Lipovetsky, G. (2007). A Felicidade Paradoxal: Ensaio dobre a sociedade de hiperconsumo. Lisboa: Edições 70.

25. McDougall, G., \& Levesque, T. (1998). Designing the Service Guarantee: unconditional or specific? Journal of Services Marketing. 12(4-5), 278-93.

26. Mestriner, F. (2005). O retrato do consumidor de embalagem. Revista Leite \& Derivados, São Paulo, 14(82), 38.

27. Morgan, R.M., \& Hunt, S.D. (1994). The commitment-trust theory of relationship marketing. Journal of Marketing, 58, 20-38.

28. Nogueira, J.G., Abreu, J.A. P., Paixão, C.H.O.S., \& Oliveira, R.C. (2008, julho). A embalagem como componente estratégico do marketing para lançamento do produto. Congresso Nacional de Excelência em Gestão, Niterói, RJ, Brasil, 4.

29. Penchansky, D.B.A., \& Thomas, J.W. (1981). The concept of access - definition 
and relationship to consumer satisfaction. Med Car, 19(2) ,127-40.

30. Pereira, J. C. R. (1999) Análise de dados qualitativos. São Paulo: EDUSP.

31. Perreault, W.D., Jr., \& McCcarthy, E. J. (2002) Princípios de Marketing. Rio de janeiro: LTC.

32. Rheingantz, P. A. (2001). Uma pequena digressão sobre conforto ambiental e qualidade de vida nos centros urbanos. Cidade \& Ambiente. Universidade Federal de Santa Maria (UFSM), 1(22), 35-58.

33. Rich, M. K., Smith, D.C. (2000). Determining relationship skillsmof prospective salespeople. Journal of Business \& Industrial Marketing, 15(4-5), 242-59.

34. Sant'anna, A.S., Moraes, L.F.R., \& Kilimnik, Z.M. (2002, setembro). Competências individuais requeridas, modernidade rrganizacional e satisfação no trabalho: uma análise de organizações mineiras sob a ótica de profissionais da área de administração. Anais do Encontro Nacional da Associação Nacional de Pós Graduação e Pesquisa em Administração, Salvador, BA, Brasil, 26.

35. Santos, C.P., \& Fernandes, D. V.D. H. (2008). A Recuperação de Serviços Como Ferramenta de Relacionamento e Seu Impacto na Confiança e Lealdade dos Clientes. RAE - Revista de Administração de Empresas, 48(1), 10-24.
36. Schmid, A.L. (2005). A Ideia de Conforto: Reflexões sobre o ambiente construído. Curitiba: Pacto Ambiental.

37. Scitovsky, T. (1992). The joyless economy: the psychology of human satisfaction. New York: Oxford University Press.

38. Selltiz, C., Jahoda, M., Deutsch, M. \& Cook, S.W. (1975). Métodos de pesquisa nas relações sociais. São Paulo: EDUSP.

39. Sheth, J.N., Parvatiyar, A. (1995). Relationship Marketing in consumer markets: antecedents and consequences. Journal of the Academy of Marketing Science, 23(4), 25571.

40. Sirdeshmukh, D., Singh, S., \& Sabol, B. (2002). Consumer trust, value and loyalty in relational exchanges. Journal of Marketing, 66(1), 15-38.

41. Slater, K. (1986). The Assessment of Comfort. Journal Textile Institute, 77(3), 157171.

42. Spake, D.F., Beatty, S.E., Brockman, B.K., \& Crutchfield, T.N. (2003, May). Consumer comfort in service relationships: Measurement and importance. Journal of Service Research : JSR, 5(4), 316-332.

43. Urbano, L., Jr, (2013). Rolling Stones: esgotando ingressos em 3 minutos. Recuperado em 07 de abril, 2013, em http://whiplash.net/materias/news_828/17 6934-rollingstones.html\#ixzz2PpZ9Gzzk. 
44. Watanabe, I. (1998). Erhart Elementos de anatomia humana: Sistema nervoso e órgãos dos sentidos ( 9 a ed.). São Paulo: Atheneu, 2000.

45. Westbrook, R. A. (1987)

Product/consumption-based responses and postpurchase processes. Journal of Marketing Research, 24(3), 258270.

46. Wilder, J. W., Jr. (1981). New concepts in technical trading systems. NY: Trends Research; 1981. 